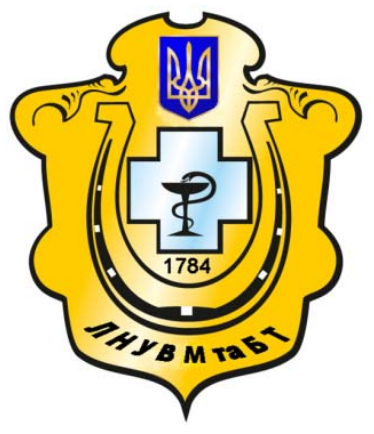

Науковий вісник Львівського національного університету ветеринарної медицини та біотехнологій імені С.3. Гжицького

Scientific Messenger of Lviv National University of Veterinary Medicine and Biotechnologies named after S.Z. Gzhytskyj

doi:10.15421/nvlvet7155

ISSN 2413-5550 print

ISSN 2518-1327 online

$\underline{\text { http://nvlvet.com.ua/ }}$

УДК 619:576.8:619:616.99:636.4

\title{
Показники антилізоцимної та антикомплементарної активності мікроорганізмів дистального відділу кишечника поросят за змішаної нематодозно-протозоозної інвазії
}

\author{
Р.А. Пеленьо \\ andriyovich30@rambler.ru \\ Львівський національний університет ветеринарної медицини та біотехнологій імені С.3. Гжицького, \\ вул. Пекарська, 50, м. Львів, 79050, Україна
}

\begin{abstract}
У статті наведені результати дослідження впливу кишкових паразитів на показники антилізоцимної та антикомплементарної активності мікроорганізмів дистального відділу кишечнику. Встановлено, щуо продукти життєдіяльності кищкових паразитів поросят знижують антилізоцимну активність таких облігатних анаеробів, як Bifidobacterium spp. на 42,1\% (p < 0,01), Prevotella spp. - на 14,3\%, Clostridium spp. - на 66,7\% (p<0,001). 3 МАФАнМ на 38,5\% (p<0,05) знижують у Lactobacillus spp. i на 50,0\% ( $<$ <,01) - y Streptococcus spp. Вищою, порівняно із контролем, антилізоцимна активність була у Bacteroides spp. $(p<0,05)$, Eubacterium spp. $(p<0,001)$, Propionibacterium spp. $(p<0,01)$, Peptostreptococcus spp. $(p<0,05)$, Fusobacterium spp. $(p<0,01)$, E. coli лакт. «+» гем «-» $(p<0,05)$, Klebsiella spp. $(p<0,001)$, Citrobacter spp. $(p<0,01)$, Enterococcus spp. $(p<0,05)$, Staphylococcus spp. $(p<0,001)$, Candida spp. $(p<0,001)$, виділених із дистального відділу кишечнику поросят, уражених змішаною нематодозно-протозоозною інвазією.

За дії продуктів життедіяльності аскарисів, еймерій та балантидій антикомплементарна активність вірогідно зростала у Prevotella spp. $(p<0,01)$, Clostridium spp. $(p<0,001)$, Eubacterium spp. $(p<0,001)$, Propionibacterium spp. $(p<0,001)$, Peptostreptococcus spp. ( $p<0,001)$, Fusobacterium spp. $(p<0,001)$, Lactobacillus spp. $(p<0,05)$, E. coli лакт. «+》 гем «-» $(p<0,01)$, E. coli лакт. «-» гем «+» $(p<0,001)$, Klebsiella spp. $(p<0,05)$, Enterobacter spp. $(p<0,001)$, Enterococcus spp. $(p<0,001)$, Streptococcus spp. $(p<0,001)$ і лише у Bacteroides spр. вона була вірогідно нижчою $(p<0,001)$, порівняно з контролем.
\end{abstract}

Ключові слова: поросята, кишечник, змішана інвазія, антилізоцимна активність, антикомплементарна активність, анаеробна мікрофлора, аеробна мікрофлора, умовно-патогенна мікрофлора.

\section{Показатели антилизоцимной и антикомплементарной активности микроорганизмов дистального отдела кишечника поросят при смешаной нематодозно-протозоозной инвазии}

\author{
Р.А. Пеленьо \\ andriyovich30@rambler.ru
}

\begin{abstract}
Львовский национальный университет ветеринарной медицины и биотехнологий имени С.3. Гжицекого, ул. Пекарская, 50, г. Львов, 79050, Украина
\end{abstract}

В статье приведены результаты исследования влияния кишечных паразитов на показатели антилизоцимной и антикомплементарной активности микроорганизмов дистального отдела кишечника. Установлено, что продукты жизнедеятельности кишечных паразитов поросят снижают антилизоцимную активность следующих облигатных анаэробов: Bifidobacterium spp. - на 42,1\% ( $<<0,01)$, Prevotella spp. - на 14,3\%, Clostridium spp. - на 66,7\% (p <0,001). C MAФAнM на 38,5\% ( $<<0,05)$ снижают у Lactobacillus spp. и на 50,0\% ( $<0,01)$ - в Streptococcus spp. Сравнительно с контролем, антилизоцимная активность была выше у Bacteroides spp. ( $p<0,05)$, Eubacterium spp. $(p<0,001)$, Propionubacterium spp.

Citation:

Peleno, R.A. (2016). The indicators of anti lysozyme and anti complementary activity of microorganism of pigs intestine distal department for mixed - protoozic invasion. Scientific Messenger LNUVMBT named after S.Z. Gzhytskyj, 18, 3(71), 248-251. 
$(p<0,01)$, Peptostreptococcus spp. $(p<0,05)$, Fusobacterium spp. $(p<0,01)$, E. coli лакто. «+» гем «-« $(p<0,05)$, Klebsiella spp. $(p<0,001)$, Citrobacter spp. $(p<0,01)$, Enterococcus spp. $(p<0,05)$, Staphylococcus spp. $(p<0,001)$, Candida spp. ( $p<$ 0,001), выделенных из дистального отдела кимечника поросят со смешанной нематодозно-протозоозной инвазией.

Под действием продуктов жизнедеятельности аскарисов, эймерий и балантидий антикомплементарная активность достоверно возрастала в Prevotella spp. $(p<0,01)$, Clostridium spp. $(p<0,001)$, Eubacterium spp. $(p<0,001)$, Propionubacterium spp. $(p<0,001)$, Peptostreptococcus spp. $(p<0,001)$, Fusobacterium spp. $(p<0,001)$, Lactobacillus spp. $(p<0,05)$, E. coli лакто. «+» гем «-» $(p<0,01)$, E. coli лакто. «-» гем «+» $(p<0,001)$, Klebsiella spp. $(p<0,05)$, Enterobacter spp. $(p<0,001)$, Enterococcus spp. $(p<0,001)$, Streptococcus spp. $(p<0,001)$ и только в Васtеroides spp. она была достоверно ниже $(p<0,001)$ по сравнению с контролем.

Ключевые слова: поросята, кишечник, смешанная инвазия, антилизоцимная активность, антикомплементарная активность, анаэробная микрофлора, аэробная микрофлора, условно-патогенная микрофлора.

\title{
The indicators of anti lysozyme and anti complementary activity of microorganism of pigs intestine distal department for mixed - protoozic invasion
}

\author{
R.A. Peleno \\ andriyovich30@rambler.ru \\ Lviv National University of Veterinary Medicine and Biotechnologies named after S.Z. Gzhytskyj, \\ Pekarska Str., 50, Lviv, 79050, Ukraine
}

\begin{abstract}
The article deals with the results of search of the influence of intestinal parasites on the indicators of antilysozyme and anticomplementary activity of microorganism of distal department of intestine. It was established, that the products of intestinal parasites of pigs reduce anti lysozyme activity of such obligate anaerobes as Bifidobacterium spp. to $42.1 \%(p<0.01)$, Prevotella spp. to 14.3\%, Clostridium spp. to $66.7 \%(p<0,001)$. With MAFAnM to $38.5 \%(p<0.05)$ in Lactobacillus spp. and to 50.0\% $(p<0.01)$ in Streptococcus spp. Higher compared with the control, antilysozyme activity was in Bacteroides spp. ( $p<0.05)$, Eubacterium spp. $(p<0,001)$, Propionibacterium spp. $(p<0.01)$, Peptostreptococcus spp. $(p<0.05)$, Fusobacterium spp. $(p<0.01)$, E. coli lact. «+» hem «-» $(p<0.05)$, Klebsiella spp. ( $p<0.001)$, Citrobacter spp. $(p<0.01)$, Enterococcus spp. $(p<0.05)$, Staphylococcus spp. $(p<0.001)$, Candida spp. $(p<0.001)$ abstracted from the distal intestine of pigs affected with mixed nematodosis - protoozic invasion. With the action of products of vital functions of ascarices, eymeria and balantides, the anticomplementary activity significantly increases in Prevotella spp. ( $p<0.01)$, Clostridium spp. $(p<0.001)$, Eubacterium spp. $(p<0.001)$, Propionibacterium spp. $(p<0.001)$, Peptostreptococcus spp. $(p<0,001)$, Fusobacterium spp. $(p<0.001)$, Lactobacillus spp. $(p<0.05)$, E. coli lact. «+» hem «-» $(p<0.01)$, E. coli lact. «-» hem «+» $(p<0.001)$, Klebsiella spp. $(p<0.05)$, Enterobacter spp. $(p<0.001)$, Enterococcus spp. $(p<0.001)$, Streptococcus spp. $(p<0.001)$ and only in Bacteroides spp. it was significantly lower $(p<0.001)$, compared with the control.
\end{abstract}

Key words: pigs, intestines, mixed invasion, antilysozyme activity, anticomplementary activity, anaerobic microflora, aerobicmicro flora, pathogenic microflora.

\section{Вступ}

Дія екологічних і сезонних чинників, неповноцінна годівля, застосування антибактеріальних препаратів, незрілість імунної системи у молодих тварин, а також кишкові паразити $\epsilon$ основними причинами мікробіологічних порушень у кишечнику і формування осередків хронічної інфекції, зумовленої умовнопатогенними мікроорганізмами (УПМ) (Bondarenko, 2000; Masljanko and Bozhyk, L.Ja. (2011). Діагностика таких інфекцій $\epsilon$ утрудненою. Це пов'язано з відсутністю специфічної клінічної картини, поліетіологічністю захворювань, висіванням 3 патологічного матеріалу асоціацій із представників нормальної мікрофлори ураженої частини кишечнику і транзиторних мікроорганізмів. Крім цього, вчені звертають увагу й на таку здатність мікроорганізмів, як секреція ними антидефенсинів, що інактивують захисні механізми хазяїна - лізоцим та комплемент (Brudastov et al., 1996). Саме тому здатність бактерій специфічно інактивувати лізоцим макроорганізму було визначено як антилізоцимну активність (АЛА), а деградувати комплемент - як антикомплементарну активність (АКА).
Роль АЛА полягає в персистенції мікроорганізмами в організмі господаря лізоциму як чинника імунітету, який входить до низки провідних бактерицидних ферментних систем клітин фагоцитарного ряду та інших клітин і тканин організму (Buharin et al., 1984; Buharin, 1994).

Антикомплементарна активність $є$ складовою персистентного потенціалу, яким володіють стафілококи, стрептококи, нейсерії, псевдомонади та інші мікроорганізми (Brudastov, 1992). Патогени, що володіють АКА, здатні утворювати більш стійкі біоценози, ніж ті, що не мають цієї здатності (Menkus, 2012).

Досі не вивченими залишаються питання впливу кишкових паразитів на секреторні фактори персистенції мікроорганізмів кишечника поросят, що робить такі дослідження актуальними.

Метою роботи було вивчити АЛА й АКА мікроорганізмів дистального відділу кишечнику за змішаної протозоозно-нематодозної інвазії поросят.

\section{Матеріал і методи досліджень}

В експериментах in vitro використовували мікроорганізми, виділені з мікробоценозу дистального відді- 
лу кишечнику інтактних поросят (контрольна група) та поросят, уражених асоціацією «аскариси+еймерії+балантидії» (дослідна група). При формуванні дослідної групи враховували інтенсивність інвазії (II) гельмінтами і найпростішими, яку визначали методом McMaster (Vasil'eva, 1995). Так, кількість ооцист балантидій в 1 г калу становила $752,9 \pm 64,7$, еймерій $-639,1 \pm 49,4$, яєць аскарисів - 626,3 $\pm 26,1$ екземплярів.

Відбір матеріалу для дослідження проводили індивідуально із прямої кишки в стерильні пеніцилінові флакони. Час від моменту забору проб до моменту ня бактеріологічних досліджень наважку вмісту масою 1 г ретельно розтирали в стерильній ступці з 9 мл стерильного буферного розчину. 3 основного розведення виготовляли наступні, починаючи $310^{2}$ та до $10^{12}$. Висів суспензії в кількості $0,05-0,1-1,0$ мл робили на Schaedler-arap, ентерокок-агар, жовтково-сольовий агар, кров'яний агар, вісмут-сульфіт-агар, середовища Ендо і Плоскірєва, агар Сабуро.

Антилізоцимну активність (АЛА) визначали за мікробіологічним методом, розробленим О. В. Бухаріним та співавторами (Buharin, et al., 1984). АКА визначали методом кінетичного титрування комплемендосліджень не перевищував 2-х годин. Для проведен-

ту з вимірюванням (як міри активності комплементу) максимальної швидкості лізису сенсибілізованих еритроцитів барана (Brudastov, 1992).

Одержані результати піддавали статистичній обробці, яку проводили методом варіаційної статистики 3 визначенням середніх значень величин і середньої похибки. Вірогідність відмінностей між середніми значеннями під час проведення аналізу оцінювали, використовуючи критерії Стьюдента (t). Відмінність між величинами вважали вірогідною, коли ймовірність різниці становила $\mathrm{p} \leq 0,05$.

\section{Результати та їх обговорення}

Встановлено, що продукти життєдіяльності кишкових паразитів поросят впливають на такі чинники персистенції мікроорганізмів всередині макроорганізму, як антилізоцимна та антикомплементарна активність. Дослідження антилізоцимної активності облігатних анаеробів, виділених 3 дистального відділу кишечнику інвазованих поросят, показало (табл. 1), що вона знижується, порівняно з контролем, на 42,1\% у Bifidobacterium spp. ( $<<0,01)$, на 14,3\% - у Prevotella spp. і на $66,7 \%$ - у Clostridium spp. $(\mathrm{p}<0,001)$.

Таблиия 1

Показники антилізоцимної та антикомплементарної активності облігатних анаеробів, виділенихі 3 дистального відділу кишечнику поросят, уражених змішаною нематодозно-протозоозною інвазісю, $\mathbf{M} \pm \mathbf{m}, \mathbf{n = 8}$

\begin{tabular}{|l|c|c|c|c|}
\hline \multirow{2}{*}{\multicolumn{2}{|}{ Мікроорганізми }} & \multicolumn{2}{|c|}{ Антилізоцимна активність, мкг/мл } & \multicolumn{2}{c|}{$\begin{array}{c}\text { Антикомплементарна активність, } \\
\text { антиСН }\end{array}$} \\
\cline { 2 - 5 } & Контроль & Дослід & Контроль & Дослід \\
\hline Bifidobacterium spp. & $1,9 \pm 0,18$ & $1,1 \pm 0,10^{* *}$ & $0,3 \pm 0,04$ & $0,1 \pm 0,02^{* *}$ \\
\hline Bacteroides spp. & $1,2 \pm 0,10$ & $1,7 \pm 0,14^{*}$ & $3,8 \pm 0,32$ & $6,1 \pm 0,56^{* *}$ \\
\hline Prevotella spp. & $1,4 \pm 0,12$ & $1,2 \pm 0,10$ & $0,2 \pm 0,01$ & $0,6 \pm 0,03^{* * *}$ \\
\hline Clostridium spp. & $0,3 \pm 0,02$ & $0,1 \pm 0,01^{* * *}$ & $0,1 \pm 0,01$ & $0,2 \pm 0,01^{* * *}$ \\
\hline Eubacterium spp. & $0,6 \pm 0,07$ & $1,6 \pm 0,13^{* * *}$ & $1,2 \pm 0,03$ & $4,3 \pm 0,36^{* * *}$ \\
\hline Propionibacterium spp. & $0,2 \pm 0,01$ & $0,4 \pm 0,05^{* *}$ & $2,4 \pm 0,16$ & $7,2 \pm 0,66^{* * *}$ \\
\hline Peptostreptococcus spp. & $0,4 \pm 0,03$ & $0,5 \pm 0,02^{*}$ & $0,3 \pm 0,03$ & $0,9 \pm 0,04^{* * *}$ \\
\hline Fusobacterium spp. & $0,3 \pm 0,02$ & $1,1 \pm 0,10^{* *}$ & $1,1 \pm 0,08$ & $3,9 \pm 0,34^{* * *}$ \\
\hline
\end{tabular}

Примітка: *-p $<0,05 ; * *-\mathrm{p}<0,01 ; * * *-\mathrm{p}<0,001$

У всіх інших облігатних анаеробів, які були досліджені, цей показник був вищим, порівняно із контролем, в 1,42 раза у Bacteroides spp. $(\mathrm{p}<0,05), 2,67$ раза - y Eubacterium spp. $(\mathrm{p}<0,001), 2,0$ раза - y Propionibacterium spp. $(\mathrm{p}<0,01), 1,25$ раза $-\mathrm{y}$ Peptostreptococcus spp. $(\mathrm{p}<0,05)$ і в 3,67paza - у Fusobacterium spp. $(\mathrm{p}<0,01)$.

Вивчення антикомплементарної активності показало, що вона властива всім облігатним анаеробним мікроорганізмам, які були ізольовані з дистального відділу кишечнику поросят. Встановлено, що продукти життєдіяльності кишкових паразитів зумовили вірогідне зростання антикомплементарної активності y Prevotella spp. $(\mathrm{p}<0,01)$, Clostridium spp. $(\mathrm{p}<0,001)$, Eubacterium spp. ( $\mathrm{p}<0,001)$, Propionibacterium spp. ( $\mathrm{p}<0,001)$, Peptostreptococcus spp. $(\mathrm{p}<0,001)$, Fusobacterium spp. $(\mathrm{p}<0,001)$ і лише у Bacteroides spp. вказаний показник був вірогідно нижчим $(\mathrm{p}<0,001)$ порівняно з контролем.

Персистентні властивості були виявлені нами й серед мезофільних аеробних і факультативно анаеро- бних мікроорганізмів (МАФАнМ), ізольованих із дистального відділу кишечнику поросят (табл. 2).

За дії продуктів життєдіяльності кишкових паразитів вірогідно зростала антилізоцимна активність $E$. coli лакт. «+» гем «-» $(\mathrm{p}<0,05)$, Klebsiella spp. $(\mathrm{p}<0,001)$, Citrobacter spp. $(\mathrm{p}<0,01)$, Enterococcus spp. $(\mathrm{p}<0,05)$, Staphylococcus spp. $(\mathrm{p}<0,001)$, Candida spp. (p < 0,001). Проте у таких мікроорганізмів, як Lactobacillus spp., Streptococcus spp. антилізоцимна активність знизилася, порівняно з контролем, відповідно на 38,5\% $(\mathrm{p}<0,05)$ та 50,0\% $(\mathrm{p}<0,01)$.

Для усіх МАФАнМ, виділених із дистального відділу кишечнику поросят, уражених змішаною нематодозно-протозоозною інвазією, характерним було зростання антикомплементарної активності, проте вірогідно вищою, порівняно 3 контролем, різниця була у Lactobacillus spp. ( $<<0,05)$, E. coli лакт. «+» гем «-» $(\mathrm{p}<0,01)$, E. coli лакт. «-» гем «+» $(\mathrm{p}<0,001)$, Klebsiella spp. $(\mathrm{p}<0,05)$, Enterobacter spp. $(\mathrm{p}<0,001)$, Enterococcus spp. $(\mathrm{p}<0,001)$ i Streptococcus spp. $(\mathrm{p}<0,001)$. 
Таблиия 2

Показники антилізоцимної та антикомплементарної активності МАФАнМ виділених із дистального відділу кишечнику поросят, уражених змішаною нематодозно-протозоозною інвазією, $\mathbf{M} \pm \mathbf{m}, \mathbf{n}=8$

\begin{tabular}{|c|c|c|c|c|}
\hline \multirow[t]{2}{*}{ Мікроорганізми } & \multicolumn{2}{|c|}{$\begin{array}{c}\text { Антилізоцимна активність, мкг/мл } \\
\text { OD }\end{array}$} & \multicolumn{2}{|c|}{$\begin{array}{c}\text { Антикомплементарна активність, } \\
\text { анти } \mathrm{CH}_{50}\end{array}$} \\
\hline & Контроль & Дослід & Контроль & Дослід \\
\hline Lactobacillus spp. & $2,6 \pm 0,32$ & $1,6 \pm 0,20^{*}$ & $1,3 \pm 0,12$ & $1,9 \pm 0,20^{*}$ \\
\hline E. coli лакт. «+»» гем «-»» & $1,2 \pm 0,12$ & $1,8 \pm 0,20^{*}$ & $2,8 \pm 0,14$ & $3,9 \pm 0,28 * *$ \\
\hline E. coli лакт. «-»» гем «+»》 & $1,5 \pm 0,18$ & $1,6 \pm 0,12$ & $2,0 \pm 0,16$ & $8,6 \pm 0,68 * * *$ \\
\hline Klebsiella spp. & $0,4 \pm 0,05$ & $2,4 \pm 0,28 * * *$ & $3,4 \pm 0,34$ & $4,8 \pm 0,38 *$ \\
\hline Enterobacter spp. & $1,9 \pm 0,16$ & $2,2 \pm 0,26$ & $0,9 \pm 0,05$ & $5,7 \pm 0,52 * * *$ \\
\hline Citrobacter spp. & $0,8 \pm 0,06$ & $1,6 \pm 0,20 * *$ & $0,6 \pm 0,03$ & $0,7 \pm 0,06$ \\
\hline Enterococcus spp. & $0,8 \pm 0,06$ & $1,2 \pm 0,12^{*}$ & $0,5 \pm 0,06$ & $1,3 \pm 0,04 * * *$ \\
\hline Streptococcus spp. & $0,6 \pm 0,06$ & $0,3 \pm 0,02^{* *}$ & $0,2 \pm 0,02$ & $1,5 \pm 0,10 * * *$ \\
\hline Staphylococcus spp. & $0,1 \pm 0,02$ & $0,9 \pm 0,04 * * *$ & $2,1 \pm 0,16$ & $2,6 \pm 0,18$ \\
\hline Candida spp. & $0,6 \pm 0,07$ & $1,4 \pm 0,10 * * *$ & $1,5 \pm 0,14$ & $1,8 \pm 0,16$ \\
\hline
\end{tabular}

\section{Висновки}

1. Продукти життєдіяльності кишкових паразитів поросят, знижують антилізоцимну активність таких облігатних анаеробів, як Bifidobacterium spp. на $42,1 \%(\mathrm{p}<0,01)$, Prevotella spp. - на 14,3\%, Clostridium spp. - на 66,7\% (p <0,001). 3 МАФАнМ на $38,5 \% \quad(\mathrm{p}<0,05)$ у Lactobacillus spp. і на $50,0 \%$ $(\mathrm{p}<0,01)$ - y Streptococcus spp. та сприяють іï зростанню, порівняно із контролем, у Bacteroides spp. $(\mathrm{p}<0,05), \quad$ Eubacterium $\quad$ spp. $\quad(\mathrm{p}<0,001)$, Propionibacterium spp. $(\mathrm{p}<0,01)$, Peptostreptococcus spp. $(\mathrm{p}<0,05)$, Fusobacterium spp. $(\mathrm{p}<0,01)$, E. coli лакт. «+» гем «-» $(\mathrm{p}<0,05)$, Klebsiella $\mathrm{spp} .(\mathrm{p}<0,001)$, Citrobacter spp. $(\mathrm{p}<0,01)$, Enterococcus spp. $(\mathrm{p}<0,05)$, Staphylococcus spp. $(\mathrm{p}<0,001)$, Candida spp. $(\mathrm{p}<$ 0,001).

2. За впливу дії кишкових паразитів та продуктів їх життєдіяльності антикомплементарна активність вірогідно зростала у Prevotella spp. (p <0,01), Clostridium spp. $(\mathrm{p}<0,001)$, Eubacterium spp. $(\mathrm{p}<$ 0,001), Propionibacterium spp. ( $<<0,001)$, Peptostreptococcus spp. ( $\mathrm{p}<0,001)$, Fusobacterium spp. $(\mathrm{p}<0,001)$, Lactobacillus spp. $(\mathrm{p}<0,05)$, E. coli лакт. «+» гем «-» $(\mathrm{p}<0,01)$, E. coli лакт. «-» гем «+» $(\mathrm{p}<0,001)$, Klebsiella spp. $(\mathrm{p}<0,05)$, Enterobacter spp. $(\mathrm{p}<0,001)$, Enterococcus spp. (p $<0,001)$, Streptococcus spp. $(\mathrm{p}<0,001)$ і лише у Bacteroides spp. вона була вірогідно нижчою $(\mathrm{p}<0,001)$ порівняно $з$ контролем.

\section{Бібліографічні посилання}

Bondarenko, V.M. (2000). Obshhij analiz predstavlenij o patogennyh i uslovno-patogennyh bakterijah. Zhurnal mikrobiologii, jepidemiologii i immunologii. 4, 20-26 (in Russian).

Brudastov, Ju.A., Valyshev, A.V., Brudastov, A.N. (1996). Antikomplementarnaja aktivnost' proizvodstvennogo shtamma Bacillus cereus IP 5832 i jenterobakterij pri ih sovmestnom kul'tivirovanii. Zhurn. mikrobiol. 3, 91-93 (in Russian).

Buharin, O.O. (1994). Biomedicinskie aspekty persistencii bakterij. Zhurn. mikrobiol. 4, 4-13 (in Russian).

Buharin, O.V., Nemceva, N.V., Anan'ina, G.E., Sidorov, V.V. (1984). Antilizocimnaja aktivnost' vnutrikletochno parazitirujushhih bakterijrin. Faktory estestvennogo immuniteta pri razlichnyh fiziologicheskih i patologicheskih sostojanijah. Tezisy dokladov k VIII zonal'noj nauchnoj konferencii. Cheljabinsk. 9, 180 (in Russian).

Brudastov, Ju.A. (1992). Antikomplementarnaja aktivnost' bakterij. Avtoref. dis. kand. med. nauk. Cheljabinsk (in Russian).

Vasil'eva, Z.G. (1995). Metody gel'mintologicheskih issledovanij. M.: Medgiz (in Russian).

Masljanko, R.P., Bozhyk, L.Ja. (2011). Rol' umovnopatogennoi' mikroflory $\mathrm{V}$ infekcijnij patologii' kyshechnyka. Naukovyj visnyk LNUVMBT imeni S.Z. G'zhyc'kogo. 13, 2(48), 185-191 (in Ukrainian)

Menkus, O.V. (2012). Vyvchennja antykomplementarnoi' aktyvnosti mikroorganizmiv u hvoryh $\mathrm{z}$ zahvorjuvannjamy dyhal'nyh shljahiv. Visnyk problem biologii' i medycyny. 2, 1(92), 116-119 (in Ukrainian).

Стаття надійшла до редакиії 15.10.2016 